\title{
Analisis Kualitas VoIP pada SCTP Menggunakan ECN dan AQM
}

\author{
La Surimi*1, MHD. Reza M.I. Pulungan ${ }^{2}$ \\ ${ }^{1}$ Program Studi S2/S3 Ilmu Komputer, FMIPA UGM, Yogyakarta \\ ${ }^{2}$ Jurusan Ilmu Komputer dan Elektronika, FMIPA UGM, Yogyakarta \\ email:*1eniac05@gmail.com,2pulungan@ugm.ac.id
}

\begin{abstract}
Abstrak
VoIP merupakan aplikasi real time yang kualitasnya sangat tergantung pada delay dan jitter, yang mana hal ini sulit dipenuhi oleh protokol yang bersifat reliable dan memiliki congestion control seperti TCP. Di sisi lain penggunaan UDP yang tidak memiliki congestion control menyebabkan peluang terjadinya congestion pada jaringan sangat besar. Penggunaan SCTP sebagai protokol alternatif juga belum mampu mengakomodasi kekurangan TCP dan UDP. Beberapa hasil penelitian menunjukkan perlu adanya perbaikan ataupun modifikasi pada mekanisme congestion control yang dimiliki oleh SCTP.

Penggunaan mekanisme ECN dan AQM pada beberapa penelitian menunjukkan bahwa kedua mekanisme ini dapat menurunkan delay dan jitter. Penelitian ini melakukan pengujian terhadap kualitas VoIP di atas SCTP yang menggunakan ECN dan AVQ pada network simulator NS2. Hasil simulasi menunjukkan bahwa penggunaan mekanisme ECN dan AVQ pada protokol SCTP menghasilkan kualitas VoIP yang lebih baik pada kondisi jaringan yang tidak ideal (high Latency low Bandwidth dan low Latency low Bandwidth dari pada penggunaan protokol SCTP tanpa menggunakan mekanisme ECN dan AVQ. Penelitian ini juga melakukan perbandingan nilai MOS panggilan VoIP SCTP yang menggunakan ECN dan AVQ dengan nilai MOS panggilan VoIP yang menggunakan protokol TCP dan UDP. Hasilnya SCTP dengan ECN dan AVQ mengungguli TCP namun belum dapat mengungguli UDP.
\end{abstract}

Kata kunci-VoIP, SCTP, ECN, AQM,AVQ.

\begin{abstract}
VoIP is the real time applications that are highly dependent on the quality of delay and jitter, which it is difficult to be met by protocol that has reliable data transfer feature and congestion control such as TCP. On the other hand the use of UDP that has no congestion control make chance of causing congestion in the network is very large. The use of SCTP as an alternative protocol was also not able to accommodate the weaknesses of TCP and UDP. Some research shows that repairs or modifications to the SCTP congestion control mechanism is needed.

The Use of ECN and AQM in some studies show that these two mechanisms can reduce delay and jitter. This study tested the quality of VoIP over SCTP with ECN and AVQ, in NS2. Simulations carried out by independent replication technique, and the results showed that ECN and $A V Q$ can increase the value of MOS VoIP calls significantly in non ideal network scenarios. This study also did comparison of SCTP MOS that uses ECN and AVQ with MOS values VoIP using TCP and UDP. The result showed that SCTP with ECN and AVQ outperform TCP but can not surpass UDP yet.
\end{abstract}

Keywords-VoIP, SCTP, ECN, AQM,AVQ. 


\section{PENDAHULUAN}

$T$ ransmission Control Protocol (TCP) dan User Datagram Protocol (UDP) merupakan dua buah transport layer yang paling banyak digunakan di internet saat ini. TCP menyediakan layanan reliable data transfer dan mekanisme congestion control TCP banyak digunakan oleh aplikasi yang menuntut reliable data transfer seperti aplikasi berbasis web dan aplikasi file transfer. Berbeda dengan TCP, UDP merupakan transport layer yang bersifat unreliable dan tidak menyediakan mekanisme congestion control. Namun karena kedua sifat itulah UDP banyak dipakai oleh aplikasi yang bersifat real time seperti aplikasi VoIP. Aplikasi real time lebih mementingkan timing guarantees dibanding reliable dan ordered data transfer. Aplikasi VoIP merupakan aplikasi real time yang sangat tergantung pada delay dan jitter, sehingga UDP merupakan pilihan terbaik sebagai transport layer.Tidak adanya congestion control pada UDP menyebabkan peluang terjadinya congestion pada jaringan sangat besar. Selain itu UDP dengan mudahakan memonopoli bandwidth pada suatu link karena sending rate Di lain pihak TCP menjadi tidak cocok dengan aplikasi yang membutuhkan end to end delay yang seminimal mungkin [1]. Beberapa tahun belakangan ini, para peneliti di bidang jaringan menawarkan beberapa transport layer baru, yang diharapkan mampu mengakomodasi kelebihan dan meminimalkan kekurangan dari TCP dan UDP. Beberapa transport layer tersebut sudah mendapatkan standarisasi dari Internet Enginering Task Force (IETF), salah satunya adalah Streaming Control Protocol (SCTP).

Beberapa penelitian sebelumnya memfokuskan pada pertanyaan apakah SCTP dapat menggantikan UDP sebagai transport layer paket VoIP. Beberapa penelitian seperti [2], [3], dan [4] menunjukkan hasil yang mengejutkan, beberapa penelitian tersebut menunjukkan bahwa tanpa adanya modifikasi pada SCTP, maka protokol ini memberikan perfoma yang tidak baik dengan delay yang cukup tinggi dalam mentransportasikan paket VoIP. Beberapa tahun belakangan ini penelitian mengenai Explicit Congestion Notification (ECN) dan Active Queue Management (AQM) sangat populer di kalangan peneliti jaringan. Berbeda dengan congestion control umumnya yang mekanismenya mengharuskan sender mengurangi congestion windownya setelah terjadinya congestion, mekanisme ECN dan AQM mampu mengirimkan feedback ke sender tentang peluang akan terjadinya congestion agar sender mengurangi congestion windownya sebelum congestion terjadi. Kemampuan ECN dan AQM mampu mengurangi drop packet rate sehingga mengurangi jitter dan delay [5]. Penggunaan ECN dan AQM pada penelitian [6] dan [7] mampu meningkatkan performa SCTP. Namun pada kedua penelitian tersebut simulasi tidak dilakukan pada aliran paket VoIP. Penelitian [5] menganalisa efek penggunaan ECN dan AQM pada kualitas aliran paket VoIP di atas protokol UDP. Hasil penelitian tersebut menunjukkan peningkatan signifikan pada kualitas panggilan aplikasi VoIP. Penelitian Reguera et al. [5] menggunakan protokol UDP sebagai transport layer aplikasi VoIP, namun sebagaimana disebutkan di atas, protokol UDP memiliki beberapa drawback pada internet. Penelitian ini akan melakukan analisa pengaruh mekanisme ECN dan AQM pada performa protokol SCTP sebagai transport layer aplikasi VoIP.

\section{METODE PENELITIAN}

Berikut adalah uraian dari tahapan dan metode yang digunakan dalam penelitian :

\subsection{Studi Kepustakaan}

Pengumpulan bahan referensi, seperti jurnal penelitian, prosiding, tesis, buku-buku teori dan sumber-sumber lain termasuk informasi yang diperoleh melalui internet.

\subsection{Analisis dan Perancangan Sistem}

Proses yang dilakukan dalam analisa dan perancangan sistem terbagi dalam beberapa bentuk diantaranya adalah sebagai berikut:

IJCCS Vol. 9, No. 2, July 2015: $121-132$ 


\subsubsection{Analisis Sistem}

Aplikasi jaringan yang bersifat real time seperti VoIP adalah aplikasi yang membutuhkan jitter dan delay yang rendah. Pada saat ini penyedia layanan VoIP di internet lebih memilih protokol UDP ketimbang protokol TCP sebagai protokol transport. Hal ini terutama dikarenakan oleh tidak adanya congestion control pada UDP. Tidak adanya congestion control pada UDP menyebabkan rate sending UDP tidak terbatasi oleh congestion control, yang akhirnya menyebabkan delay dan jiiter pada receiver sangatlah kecil. Namun seperti telah disebutkan sebelumnya hal ini menimbulkan masalah pada jaringan.

SCTP merupakan salah satu jenis protocol transport pada jaringan yang sampai sekarang masih terus dikembangkan. Desain awal SCTP ditujukan untuk membawa sinyal telepon SS7 [8] dalam jaringan IP. Kenyataan tersebut memunculkan beberapa penelitian yang mengangkat SCTP sebagai transport layer paket VoIP. Beberapa penelitian seperti [2], [3] dan [4] menunjukkan menunjukkan bahwa tanpa adanya modifikasi pada SCTP, maka protokol ini memberikan perfoma yang tidak baik dalam hal delay dan jitter yang cukup tinggi dalam mentransportasikan paket VoIP. Salah satu alasannya adalah karena sebagian besar mekanisme SCTP meniru mekanisme pada TCP, termasuk mekanisme congestion control. Penelitanpenelitian tersebut memberikan kesimpulan bahwa harus ada modifikasi pada congestion control SCTP.

ECN dan AQM dapat berperan sebagai tambahan mekanisme pada congestion control SCTP. ECN dan AQM adalah dua mekanisme yang pada beberapa penelitian menujukkan performa yang cukup baik terutama dalam hal meminimalkan delay dan jitter. Berbeda dengan congestion control umumnya yang mekanismenya mengharuskan sender mengurangi congestion window (cwnd) setelah terjadinya congestion, mekanisme ECN dan AQM mampu mengirimkan feedback ke sender tentang peluang akan terjadinya congestion agar sender mengurangi cwnd sebelum congestion terjadi. Kemampuan ECN dan AQM yang mampu mendeteksi peluang terjadinya congestion dapat mengurangi drop packet rate sehingga mengurangi jitter dan delay [5]. Oleh karena itu pada penelitian ini akan dilakukan simulasi untuk mengukur sejauh mana ECN dan AQM mempengaruhi kualitas VoIP yang berjalan di atas protokol SCTP.

\subsubsection{Perancangan Sistem}

Gambar 1 secara umum menunjukkan rancangan sistem yang akan dijalankan dalam simulasi. Rancangan sistem tersebut terdiri dari NS2VoIP++ sebagai generator traffic VoIP, SCTP agent sebagai transport layer, mekanisme ECN sebagai tambahan mekanisme congestion control pada SCTP, dan mekanisme AVQ sebagai mekanisme queue.

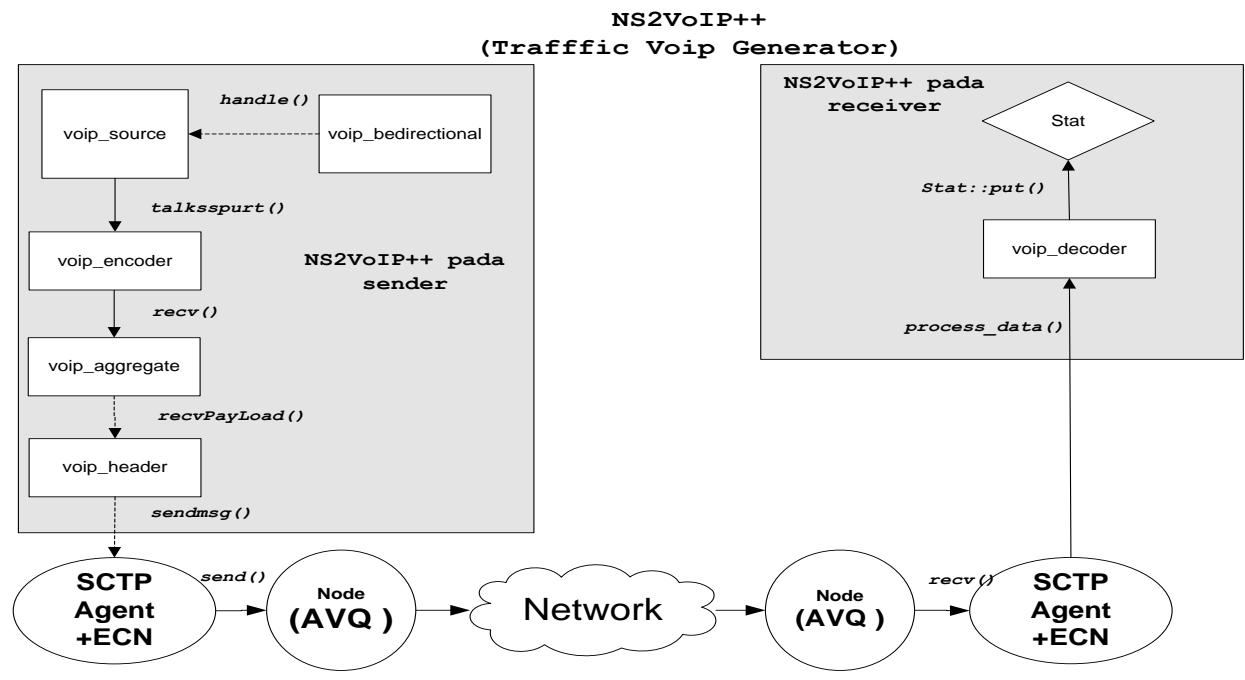

Gambar 1 Rancangan Sistem 
1. NS2VoIP++ Traffic Voip Generator)

Pada penelitian ini traffic VoIP dihasilkan oleh modul NS2VoIP++. NS2VoIP++ adalah modul yang mensimulasikan traffic VoIP pada NS2NS2VoIP++ dirancang berdasarkan model user behaviour dari aplikasi VoIP. Modul ini dapat didownload dalam bentuk patch NS2 pada NS2Voip++ pada dasarnya dirancang untuk berjalan di atas protokol UDP, sehingga dalam penelitian ini harus dilakukan modifikasi pada modul NS2VoIP++ agar dapat berkomunikasi dengan SCTP agent.

2. SCTP Agent

NS2 mulai pada versi 2.29 telah menyediakan modul untuk SCTP agent. Rancangan modul SCTP agent pada ns2 dirancang oleh Protocol Engineering Lab, Universitas Delaware. Penelitian ini menggunakan modul versi SCTP 3.5 yang terdapat pada NS2 2.34 dengan beberapa modifikasi. Modifikasi dilakukan untuk mengakomodir penambahan mekanisme ECN dan VoIP Traffic Generator NS2VoIP++.

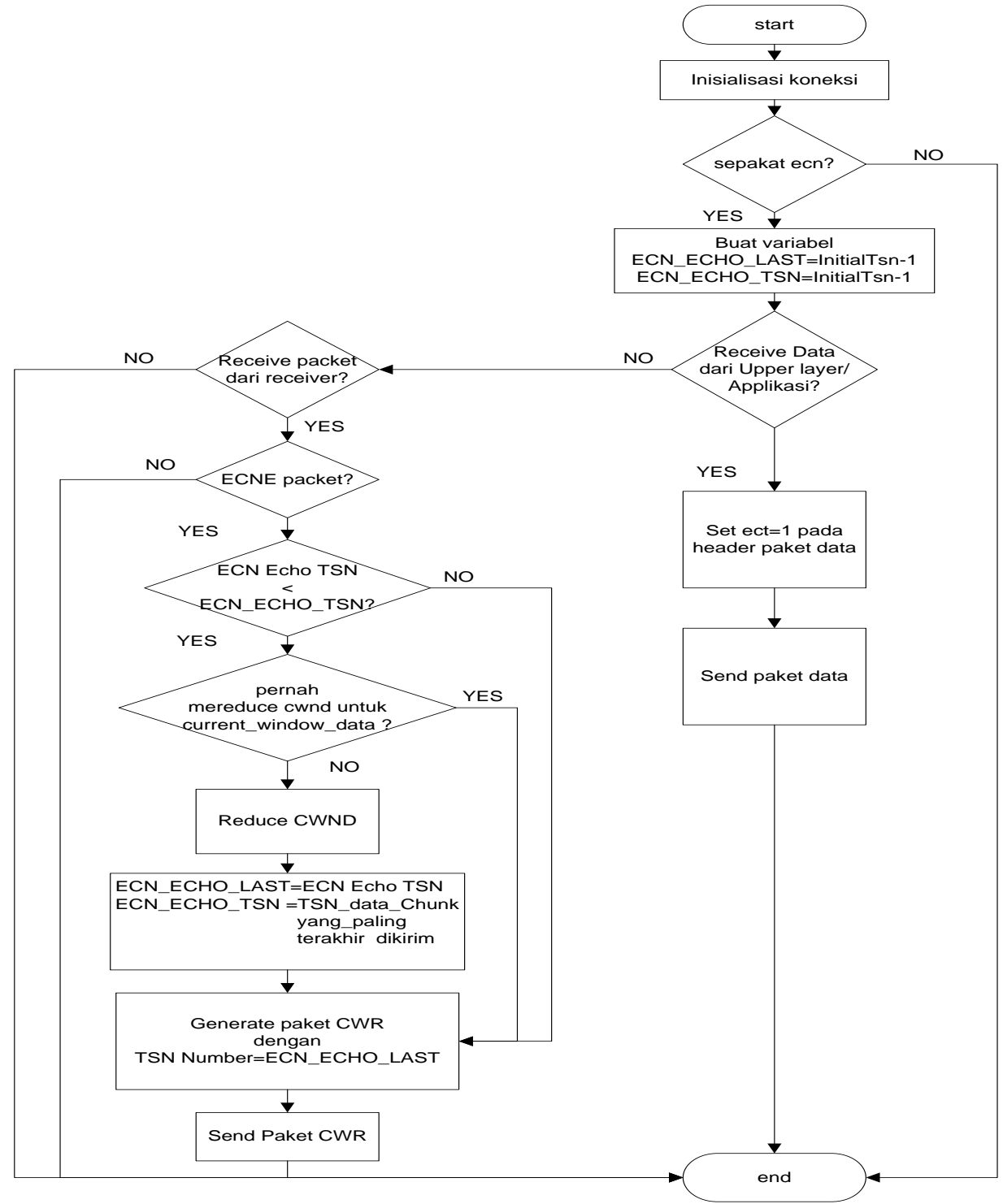

Gambar 2 Mekanisme ECN pada Sender 
3. Mekanisme ECN pada SCTP

SCTP modul versi 3.5 belum menyediakan dukungan untuk mekanisme ECN. Oleh karena itu, dilakukan modifikasi terhadap modul SCTP agent untuk menambahkan mekanisme ECN. Mekanisme ECN yang ditambahkan mengikuti prosedur dari IETF yang termuat dalam draft-stewart-tsvwg-sctpecn-05 [9].Mekanisme ECN bekerja pada sisi sender dan sisi receiver.

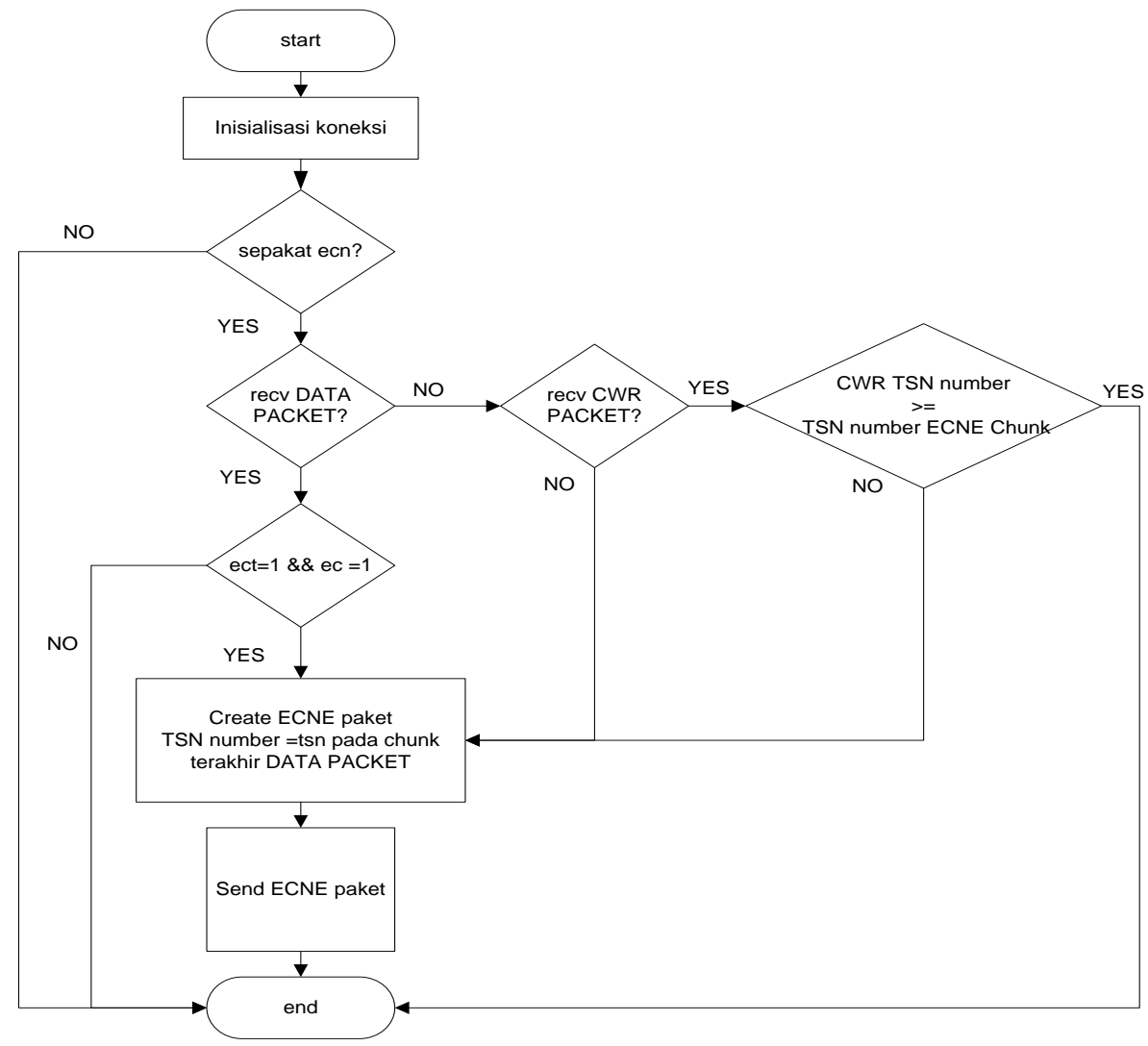

Gambar 3 Mekanisme ECN pada receiver

Gambar 2 menunjukkan diagram alir mekanisme ECN pada sender. Setelah tahap inisialisasi selesai dilakukan dan penggunaan mekanisme ECN disetujui oleh sender dan receiver maka untuk keperluan mekanisme ECN nantinya, sender akan membuat dua buah variabel, yaitu ECN_ECHO_LAST dan ECN_ECHO_TSN untuk setiap destination. Nilai inisial untuk kedua variabel ini adalah nilai InitialTSN-1. Setiap saat sender menerima data dari upper layer atau aplikasi, sebelum mengirim data yang telah dienkapsulasi menjadi paket ke receiver, mekanisme ECN mengharuskan sender untuk menset ECT header flag pada paket data dengan nilai 1. ECT header flag tersebut akan memberi tanda kepada jaringan bahwa paket tersebut mendukung mekanisme ECN. Jika sender menerima paket berupa ECNE chunk dari receiver, maka hal ini menandakan bahwa jaringan mulai mendeteksi akan terjadinya congestion. Oleh karena itu sender harus melakukan penurunan $c w n d$. Penurunan cwnd oleh sender harus dilakukan sekali dalam satu window data. Jika penurunan cwnd belum pernah dilakukan maka sender akan melakukan penurunan cwnd. Setelah melakukan penurunan $c w n d$, maka nilai $E C N \_E C H O \_T S N$ akan diset dengan nilai TSN pada DATA chunk terakhir yang telah dikirim sedangkan Nilai ECN_ECHO_LAST diset dengan nilai TSN yang ada pada ECNE chunk. Setelah mengeset kedua variable tersebut sender akan menggenerate CWR chunk dan mengirimkannya ke receiver sebagai tanda sender telah menurunkan cwnd. TSN 
number pada CWR chunk diset dengan nilai ECN_ECHO_LAST. Jika pengecekan pertama dan kedua tidak mengizinkan penurunan cwnd maka sender akan tetap menggenerate CWR chunk dan kemudian mengirimkanya ke receiver. Gambar 3 menunjukkan diagram alir mekanisme ECN pada receiver. Setelah tahap inisialisasi selesai dilakukan dan penggunaan mekanisme ECN disepakati oleh sender dan receiver. Setiap kali receiver menerima paket bertipe DATA, receiver akan mengecek ECT flag header dan EC flag header pada paket. ECT flag header bernilai 1 dan EC flag header bernilai 1 mengindikasikan jaringan memiliki peluang besar mengalami congestion. Receiver kemudian akan menggenerate ECNE chunk dengan nilai TSN number diset dengan nilai TSN chunk terakhir dalam paket DATA yang diterima. Kemudian receiver akan mengirimkan ECNE chunk tersebut dalam bentuk paket ke sender. Receiver akan terus mengirimkan ECNE chunk ke sender hingga receiver menerima CWR chunk dari sender yang nilai TSN number pada CWR chunk tersebut bernilai lebih besar sama dengan TSN number ECNE chunk yang terakhir dikirim.

4. Adaptive Virtual Queue

Pada [10] menawarkan mekanisme Adaptive Virtual Queue (AVQ) berbasis AQM. AVQ telah diimplementasikan dalam NS2 dengan nama modul $v q$ queиe

5. Lingkungan Simulasi

Rancangan topologi untuk lingkungan simulasi mengikuti rancangan simulasi yang diajukan oleh [3] ditunjukkan pada Gambar 4. Node 1 dan node 2 merupakan node router dengan panjang buffer yang terbatas. Node-node yang lain merupakan end node. Node 0 dan node 3 merupakan node VoIP dengan NS2VoIP++ sebagai pembangkit aliran VoIP. Node 4 dan node 5 digunakan untuk mensimulasikan traffic FTP dengan TCP sebagai transport agent. Node 6 dan node 7 digunakan untuk mensimulasikan HTTP traffic menggunakan modul pack mime HTTP dengan TCP sebagai transport agent. Link 1-2 digunakan secara share oleh semua aliran (aliran VoIP, FTP dan HTTP). Simulasi dilakukan menggunakan keempat skenario (hLhB, hLlB, ILhB dan ILlB) dengan mengubah-ubah ukuran bandwidth dan delay pada link $1-2$.

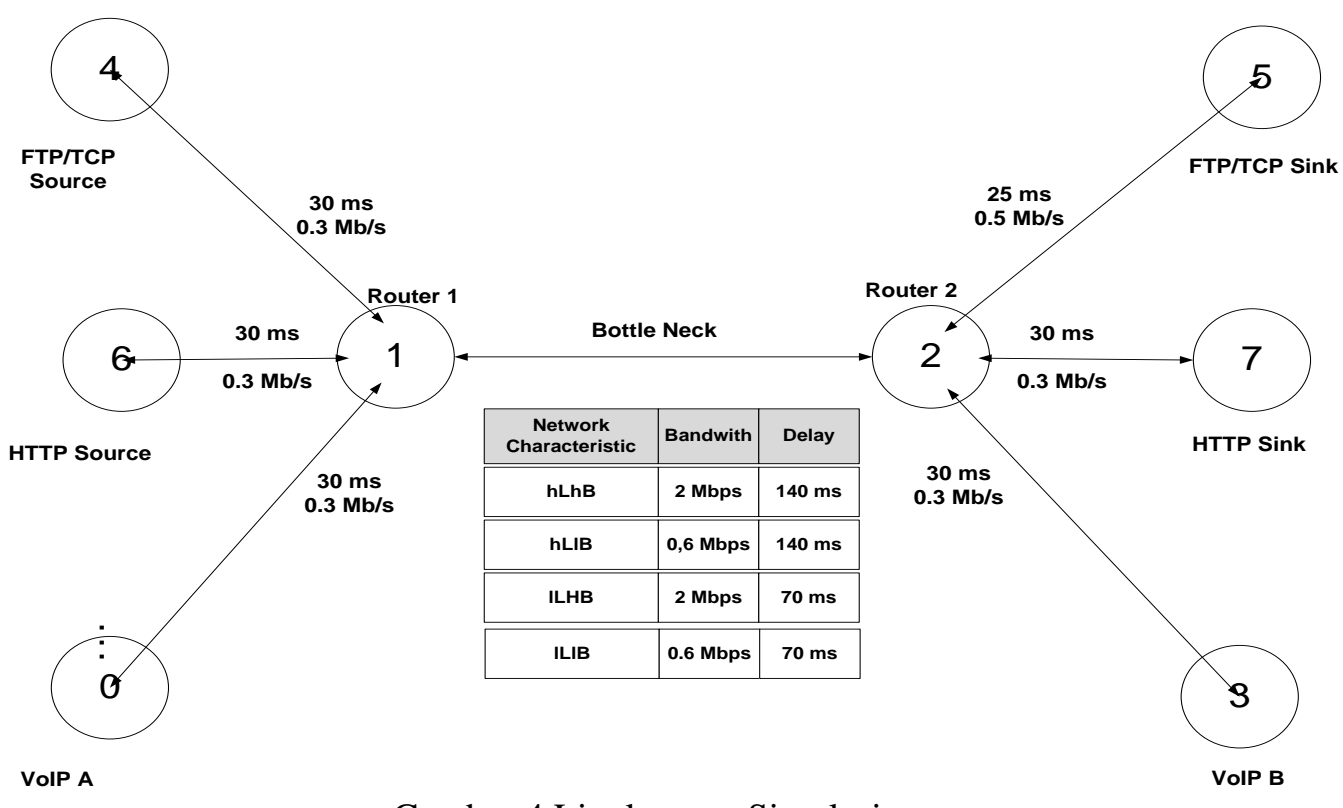

Gambar 4 Lingkungan Simulasi 
6. Rancangan Pengujian

Terdapat empat pengujian, pengujian pertama akan dilakukan terhadap kualitas VoIP yang dihasilkan oleh SCTP tanpa menggunakan ECN dan AVQ, pengujian kedua dilakukan untuk menguji kualitas VoIP yang dihasilkan oleh SCTP yang menggunakan ECN dan AVQ. Pengujian tiga dilakukan untuk menguji kualitas VoIP di atas protokol TCP. Pengujian empat dilakukan untuk menguji kualitas VoIP di atas protokol UDP. Pada masing-masing pengujian diberlakukan empat buah skenario jaringan $\mathrm{hLhB}, \mathrm{hLlB}, \mathrm{LhB}$, dan $l L l B$. Simulasi dilakukan dengan teknik independent replication, dengan jumlah replikasi maksimal sebanyak 10 kali, persentase error yang diperbolehkan sebesar 5\%, dan setiap simulasi berdurasi $300 \mathrm{~s}$.

7. Pengambilan Data kualitas VoIP

Ukuran kualitas VoIP yang diukur berupa MOS.Ukuran kualitas MOS diukur dalam bentuk average dalam satu simulasi.Nilai MOS dikonversi dari nilai R-Model persamaan (1).

$$
R=R_{0}-I_{d}-I_{e-e f}+A
$$

Dimana $R_{0}$ adalah kondisi sinyal asli tanpa noise, dengan nilai default 93,2 [11], $I_{d}$ adalah gangguan yang disebabkan oleh delay, $I_{e-e f}$ adalah gangguan yang disebabkan low bit rate codec dan packet lost, dan A adalah nilai kompensasi terhadap gangguangangguan di atas. Konversi dilakukan dengan persamaan (2).

$$
\operatorname{MOS}=\left\{\begin{array}{lr}
1 & R<0 \\
1+0,035 R+R(R-60)(100-R) 7.10^{6} & 0<R<100 \\
4,5 & R>100
\end{array}\right.
$$

8. Penarikan kesimpulan

Penarikan kesimpulan, apakah penggunaan ECN dan AVQ pada protokol SCTP mempengaruhi kualitas VoIP yang dihasilkan, dilakukan menggunakan uji statistik Wilcoxon Signed Rank.

\section{HASIL DAN PEMBAHASAN}

\subsection{Perbandingan Kualitas VoIP SCTP dengan ECN $+A V Q$ dan SCTP tanpa ECN $+A V Q$}

\subsubsection{Skenario 1, high Latency high Bandwidth (delay $140 \mathrm{~ms}$ dan bandwidth $2 \mathrm{Mbps}$ )}

Tabel 1 memperlihatkan hasil uji statistik Wilcoxon Signed Rank terhadap nilai MOS SCTP yang tidak menggunakan ECN+AVQ dan nilai MOS protokol SCTP yang menggunakan ECN+AVQ. Terlihat bahwa nilai MOS SCTP yang menggunakan ECN+AVQ lebih besar dibandingkan dengan nilai MOS SCTP yang tidak menggunakan ECN+AVQ namun uji statistik Wilcoxon Signed Rank memberikan kesimpulan perbedaan yang dihasilkan tidak signifikan. Hal ini disebabkan oleh bandwidth antara router 1 dan router 2 cukup besar hingga menyebabkan kinerja ECN+AVQ pada queue antara router 1 dan router 2 tidak maksimal. Setiap paket yang telah diproses pada router dan akan dipropagasikan ke router berikutnya tidak membebani queue terlalu berat karena bandwidth untuk propagasi cukup besar, walupun terdapat delay $140 \mathrm{~ms}$. Hal ini membuat kinerja AVQ menghampiri DropTail, sehingga nila MOS yang diperoleh tidak jauh berbeda dengan nilai MOS pada SCTP yang menggunakan DropTail. 


\subsection{2 high Latency low Bandwidth (delay $140 \mathrm{~ms}$ dan bandwidth 0.6 Mbps)}

Uji Wilcoxon Signed Rank, seperti yang ditunjukkan pada Tabel 2 memberikan kesimpulan bahwa terdapat perbedaan yang signifikan antara nilai MOS protokol SCTP yang menggunakan ECN+AVQ dengan nilai MOS protokol SCTP yang tidak menggunakan ECN+AVQ. Pada skenario kedua ini, skenario yang paling sering terjadi pada jaringan, kinerja ECN+AVQ lebih baik ketimbang skenario pertama. Bandwidth yang kecil ditambah dengan latency yang cukup besar menyebabkan paket bertumpuk di queue. AVQ melakukan mark paket lebih sering, mekanisme ECN menurunkan congestion window pada sender sehingga SCTP sender dapat menghindari kemacetan yang berujung pada rendahnya jitter dan paket loss dari SCTP yang menggunakan ECN+AVQ.

\subsubsection{Low Latency high Bandwidth (delay $70 \mathrm{~ms}$ dan bandwidth $2 \mathrm{Mbps}$ )}

Tabel 3 menunjukkan perbedaan antara nilai MOS SCTP tanpa ECN+AVQ dan nilai MOS SCTP dengan ECN+AVQ, tidaklah signifikan. Sama halnya dengan skenario pertama, pada skenario ini bandwidth yang cukup besar mengurangi kinerja AVQ+ECN, ditambah lagi oleh rendahnya latency membuat queue yang menuju ke router lain (router 1 ke router 2 dan sebaliknya) tidak terlalu terbebani oleh paket yang akan dipropagasikan. Pada kondisi seperti ini peluang terjadinya congestion sangat kecil, kualitas teknik queue DropTail menghampiri kualitas yang diberikan oleh AVQ bahkan lebih baik.

\subsubsection{Low Latency low Bandwidth (delay $70 \mathrm{~ms}$ dan bandwidth $0.6 \mathrm{Mbps}$ )}

Tabel 4 menunjukkan perbedaan yang signifikan antara protokol SCTP yang tidak menggunakan ECN+AVQ dan protokol SCTP yang menggunakan ECN+AVQ Pada skenario ini, kinerja ECN+AVQ lebih baik ketimbang skenario pertama dan ketiga. Bandwidth yang kecil menyebabkan paket bertumpuk di quеие. AVQ melakukan mark paket lebih sering, mekanisme ECN menurunkan congestion window pada sender sehingga SCTP sender dapat menghindari kemacetan yang berujung pada rendahnya jitter dan paket loss dari SCTP yang menggunakan ECN+AVQ.

Tabel 1 Hasil uji Wilcoxon Signed Rank terhadap nilai MOS SCTP dengan ECN+AVQ dan SCTP tanpa ECN+AVQ pada skenario 1

\begin{tabular}{|c|c|c|c|c|c|c|c|c|}
\hline \multirow[b]{2}{*}{$\begin{array}{l}\text { Replik- } \\
\text { asi }\end{array}$} & \multicolumn{3}{|c|}{ Kualitas MOS } & \multirow[b]{2}{*}{$\begin{array}{l}\text { Difference } \\
\text { (D) }\end{array}$} & \multirow[b]{2}{*}{$|\mathbf{D}|$} & \multirow[b]{2}{*}{$\begin{array}{c}\text { Rank } \\
|\mathbf{D}|\end{array}$} & \multirow[b]{2}{*}{$\begin{array}{c}\text { Signed } \\
\text { Rank of } \\
|D| \\
\end{array}$} & \multirow[b]{2}{*}{$\begin{array}{c}\text { SQR }\left(\sum \text { Signed }\right. \\
\text { Rank of }|\mathbf{D}|)\end{array}$} \\
\hline & SCTP & \multicolumn{2}{|c|}{$\begin{array}{c}\text { SCTP } \\
(\text { ECN+AVQ) }\end{array}$} & & & & & \\
\hline 1 & 2,1126 & \multicolumn{2}{|l|}{2,15254} & $-0,03996$ & 0,04 & 4,0 & $-4,0$ & 16 \\
\hline 2 & 2,1104 & \multicolumn{2}{|l|}{2,16429} & $-0,05387$ & 0,0539 & 5,0 & $-5,0$ & 25 \\
\hline 3 & 2,1811 & \multicolumn{2}{|l|}{2,26402} & $-0,08289$ & 0,0829 & 8,0 & $-8,0$ & 64 \\
\hline 4 & 2,1493 & \multicolumn{2}{|l|}{2,13428} & 0,01501 & 0,015 & 2,0 & 2,0 & 4 \\
\hline 5 & 2,1937 & \multicolumn{2}{|l|}{2,10656} & 0,0871 & 0,0871 & 9,0 & 9,0 & 81 \\
\hline 6 & 2,0797 & \multicolumn{2}{|l|}{2,1979} & $-0,11814$ & 0,1181 & 10,0 & $-10,0$ & 100 \\
\hline 7 & 2,1564 & \multicolumn{2}{|l|}{2,1814} & $-0,025$ & 0,025 & 3,0 & $-3,0$ & 9 \\
\hline 8 & 2,1564 & \multicolumn{2}{|l|}{2,2129} & $-0,05649$ & 0,0565 & 7,0 & $-7,0$ & 49 \\
\hline 9 & 2,1354 & \multicolumn{2}{|l|}{2,1495} & $-0,0141$ & 0,0141 & 1,0 & $-1,0$ & 1 \\
\hline 10 & 2,1276 & \multicolumn{2}{|l|}{2,1824} & $-0,05478$ & 0,0548 & 6,0 & $-6,0$ & 36 \\
\hline \multicolumn{2}{|c|}{$|\mathbf{W}|$} & 1,68 & \multicolumn{3}{|c|}{ Kesimpulan: } & \multicolumn{3}{|c|}{$|\mathbf{W}|<\mathbf{c}$} \\
\hline \multicolumn{2}{|l|}{ c } & 1,96 & \multicolumn{6}{|c|}{$\begin{array}{l}\text { Tidak Terdapat perbedaan yang signifikan antara SCTP dan } \\
\text { SCTP }(E C N+A V Q)\end{array}$} \\
\hline
\end{tabular}

IJCCS Vol. 9, No. 2, July 2015: $121-132$ 
Tabel 2 Hasil uji Wilcoxon Signed Rank terhadap nilai MOS SCTP dengan ECN+AVQ dan SCTP tanpa ECN+AVQ pada skenario 2

\begin{tabular}{|c|c|c|c|c|c|c|c|}
\hline \multirow[b]{2}{*}{ Replikasi } & \multicolumn{2}{|c|}{ Kualitas MOS } & \multirow[b]{2}{*}{$\begin{array}{l}\text { Difference } \\
\text { (D) }\end{array}$} & \multirow[b]{2}{*}{$|\mathbf{D}|$} & \multirow[b]{2}{*}{$\underset{|D|}{\operatorname{Rank}}$} & \multirow[b]{2}{*}{$\begin{array}{c}\text { Signed } \\
\text { Rank } \\
\text { of }|\mathrm{D}| \\
\end{array}$} & \multirow[b]{2}{*}{$\begin{array}{c}\operatorname{SQR}\left(\sum \text { Signed }\right. \\
\text { Rank of }|\mathbf{D}|)\end{array}$} \\
\hline & SCTP & $\begin{array}{c}\text { SCTP } \\
(\mathrm{ECN}+\mathrm{AVQ}) \\
\end{array}$ & & & & & \\
\hline 1 & 1,64344 & 1,88078 & $-0,23734$ & 0,2373 & 1,0 & $-1,0$ & 1 \\
\hline 2 & 1,54468 & 1,92765 & $-0,38297$ & 0,383 & 5,0 & $-5,0$ & 25 \\
\hline 3 & 1,58658 & 1,89037 & $-0,30379$ & 0,3038 & 3,0 & $-3,0$ & 9 \\
\hline 4 & 1,63305 & 1,92832 & $-0,29527$ & 0,2953 & 2,0 & $-2,0$ & 4 \\
\hline 5 & 1,61161 & 1,92098 & $-0,30937$ & 0,3094 & 4,0 & $-4,0$ & 16 \\
\hline 6 & 1,61872 & 1,89888 & $-0,28016$ & 0,2802 & 5,0 & $-5,0$ & 25 \\
\hline 7 & 1,69339 & 1,80013 & $-0,10674$ & 0,1067 & 2,0 & $-2,0$ & 4 \\
\hline 8 & 1,60587 & 1,89361 & $-0,28774$ & 0,2877 & 6,0 & $-6,0$ & 36 \\
\hline 9 & 1,58276 & 1,8378 & $-0,25504$ & 0,255 & 4,0 & $-4,0$ & 16 \\
\hline 10 & 1,74973 & 1,83469 & $-0,08496$ & 0,085 & 1,0 & $-1,0$ & 1 \\
\hline \multicolumn{3}{|c|}{$\sum$ Signed Rank of $|D|$} & $-33,0$ & \multicolumn{2}{|c|}{ Kesimpulan: } & \multicolumn{2}{|l|}{$|w|>c$} \\
\hline \multicolumn{3}{|c|}{ V(SQR( $(\Sigma$ Signed Rank of $|D|))$} & 11,7 & \multirow{3}{*}{\multicolumn{4}{|c|}{$\begin{array}{l}\text { Terdapat perbedaan yang signifikan antara } \\
\text { SCTP dan SCTP(ECN+AVQ) }\end{array}$}} \\
\hline & & $|w|$ & 2,82 & & & & \\
\hline & & c & 1,96 & & & & \\
\hline
\end{tabular}

Tabel 3 Hasil uji Wilcoxon Signed Rank terhadap nilai MOS SCTP dengan ECN+AVQ dan SCTP tanpa ECN+AVQ pada skenario 3

\begin{tabular}{|c|c|c|c|c|c|c|c|}
\hline \multirow[b]{2}{*}{ Replikasi } & \multicolumn{2}{|c|}{ Kualitas MOS } & \multirow[b]{2}{*}{$\begin{array}{l}\text { Difference } \\
\text { (D) }\end{array}$} & \multirow[b]{2}{*}{$|\mathbf{D}|$} & \multirow[b]{2}{*}{$\begin{array}{c}\text { Rank } \\
|\mathrm{D}|\end{array}$} & \multirow[b]{2}{*}{$\begin{array}{c}\text { Signed } \\
\text { Rank of } \\
\text { |D| }\end{array}$} & \multirow[b]{2}{*}{$\begin{array}{c}\text { SQR } \\
\text { ( } \sum \text { Signed } \\
\text { Rank of } \\
|\mathrm{D}|) \\
\end{array}$} \\
\hline & SCTP & $\begin{array}{c}\text { SCTP } \\
(\mathbf{E C N}+\mathbf{A V Q})\end{array}$ & & & & & \\
\hline 1 & 2,44611 & 2,39984 & 0,04627 & 0,0463 & 7,0 & 7,0 & 49 \\
\hline 2 & 2,39272 & 2,38548 & 0,00724 & 0,0072 & 1,0 & 1,0 & 1 \\
\hline 3 & 2,39621 & 2,43698 & $-0,04077$ & 0,0408 & 6,0 & $-6,0$ & 36 \\
\hline 4 & 2,36672 & 2,4481 & $-0,08138$ & 0,0814 & 10,0 & $-10,0$ & 100 \\
\hline 5 & 2,44881 & 2,43535 & 0,01346 & 0,0135 & 2,0 & 2,0 & 4 \\
\hline 6 & 2,44164 & 2,38992 & 0,05172 & 0,0517 & 8,0 & 8,0 & 64 \\
\hline 7 & 2,42493 & 2,44578 & $-0,02085$ & 0,0209 & 3,0 & $-3,0$ & 9 \\
\hline 8 & 2,44105 & 2,4066 & 0,03445 & 0,0345 & 5,0 & 5,0 & 25 \\
\hline 9 & 2,40752 & 2,37731 & 0,03021 & 0,0302 & 4,0 & 4,0 & 16 \\
\hline 10 & 2,32755 & 2,40017 & $-0,07262$ & 0,0726 & 9,0 & $-9,0$ & 81 \\
\hline \multicolumn{3}{|c|}{$\sum$ Signed Rank of $|\mathbf{D}|$} & $-1,0$ & \multicolumn{2}{|c|}{ Kesimpulan: } & \multicolumn{2}{|l|}{$|\mathbf{W}|<\mathbf{c}$} \\
\hline \multicolumn{3}{|c|}{$\sqrt{ }\left(\operatorname{SQR}\left(\sum\right.\right.$ Signed Rank of $\left.\left.|\mathrm{D}|\right)\right)$} & 19,6 & \multirow{3}{*}{\multicolumn{4}{|c|}{$\begin{array}{l}\text { Tidak Terdapat perbedaan yang } \\
\text { signifikan antara SCTP dan } \\
\text { SCTP(ECN+AVQ) }\end{array}$}} \\
\hline & & $|\mathbf{W}|$ & 0,05 & & & & \\
\hline & & c & 1,96 & & & & \\
\hline
\end{tabular}


Tabel 4 Hasil uji Wilcoxon Signed Rank terhadap nilai MOS SCTP dengan ECN+AVQ dan SCTP tanpa ECN $+A V Q$ pada skenario 4

\begin{tabular}{|c|c|c|c|c|c|c|c|}
\hline \multirow[b]{2}{*}{ Replikasi } & \multicolumn{2}{|c|}{ Kualitas MOS } & \multirow[b]{2}{*}{$\begin{array}{l}\text { Difference } \\
\text { (D) }\end{array}$} & \multirow[b]{2}{*}{$|\mathbf{D}|$} & \multirow[b]{2}{*}{$\begin{array}{c}\text { Rank } \\
|\mathrm{D}|\end{array}$} & \multirow[b]{2}{*}{$\begin{array}{c}\text { Signed } \\
\text { Rank } \\
\text { of } \\
|D| \\
\end{array}$} & \multirow[b]{2}{*}{ 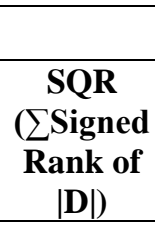 } \\
\hline & SCTP & $\begin{array}{c}\text { SCTP } \\
(\text { ECN+AVQ) }\end{array}$ & & & & & \\
\hline 1 & 2,08404 & 2,14286 & $-0,05882$ & 0,0588 & 6,0 & $-6,0$ & 36 \\
\hline 2 & 2,1155 & 2,18749 & $-0,07199$ & 0,072 & 7,0 & $-7,0$ & 49 \\
\hline 3 & 2,06395 & 2,13967 & $-0,07572$ & 0,0757 & 8,0 & $-8,0$ & 64 \\
\hline 4 & 2,02747 & 2,08433 & $-0,05686$ & 0,0569 & 5,0 & $-5,0$ & 25 \\
\hline 5 & 2,14319 & 2,13505 & 0,00814 & 0,0081 & 2,0 & 2,0 & 4 \\
\hline 6 & 2,00593 & 2,24014 & $-0,23421$ & 0,2342 & 10,0 & $-10,0$ & 100 \\
\hline 7 & 2,01159 & 2,0344 & $-0,02281$ & 0,0228 & 3,0 & $-3,0$ & 9 \\
\hline 8 & 2,13087 & 2,18048 & $-0,04961$ & 0,0496 & 4,0 & $-4,0$ & 16 \\
\hline 9 & 2,09219 & 2,09215 & $4 \mathrm{E}-05$ & $4 \mathrm{E}-05$ & 1,0 & 1,0 & 1 \\
\hline 10 & 1,96009 & 2,12986 & $-0,16977$ & 0,1698 & 9,0 & $-9,0$ & 81 \\
\hline \multicolumn{3}{|c|}{$\sum$ Signed Rank of $|D|$} & $-49,0$ & \multicolumn{2}{|c|}{ Kesimpulan: } & \multicolumn{2}{|c|}{$|W|>c$} \\
\hline \multicolumn{3}{|c|}{ V(SQR( $\sum$ Signed Rank of |D|)) } & 19,6 & \multirow{3}{*}{\multicolumn{4}{|c|}{$\begin{array}{l}\text { Terdapat perbedaan yang signifikan } \\
\text { antara SCTP dan SCTP(ECN+AVQ) }\end{array}$}} \\
\hline & & $|w|$ & 2,50 & & & & \\
\hline & & c & 1,96 & & & & \\
\hline
\end{tabular}

\subsection{Perbandingan Kualitas VoIP SCTP dengan ECN $+A V Q$, SCTP tanpa ECN+AVQ, TCP dan UDP}

Perbandingan dilakukan terhadap nilai MOS SCTP dengan ECN+AVQ, SCTP tanpa ECN+AVQ, TCP dan UDP. Hasil simulasi menunjukkan untuk semua skenario SCTP dengan ECN+AVQ memiliki kualitas MOS yang lebih baik dari TCP namun tidak lebih baik dari UDP belum dapat melebihi UDP. Perbedaan nilai MOS yang diberikan oleh TCP dan SCTP terletak pada kelebihan feature SCTP berupa kemampuan multystreaming dan teknik pempaketan chunk data. SCTP dapat mengirimkan satu paket yang berisikan beberapa chunk data dalam beberapa stream dalam satu satuan waktu namun TCP mengirimkan hanya satu chunk data dalam satu paket melalui satu stream pada satu satuan waktu. Pada skenario ini tercatat SCTP tanpa ECN+AVQ maupun SCTP yang menggunakan ECN+AVQ mengirimkan paket rata-rata sebanyak 17695 buah paket, bandingkan dengan TCP yang hanya mengirimkan 4757 buah paket. Kualitas UDP tidak terpengaruh oleh high latency maupun low bandwidth, hal ini disebabkan UDP tidak memiliki congestion control. Ketika ketiga protokol lainya menurunkan sending rate akibat congestion dan harus melakukan proses retransmisi akibat packet loss, UDP yang tidak memiliki mekanisme congestion control dan tidak bersifat reliable data transfer, tetap mengirimkan paket dengan sending rate yang konstan.

\section{KESIMPULAN}

Berdasarkan dari hasil penelitian dan pembahasan yang dilakukan maka diperoleh kesimpulan sebagai berikut:

1. Penggunaan protokol SCTP yang menggunakan mekanisme ECN dan AVQ sebagai transport layer VoIP menunjukkan performa yang lebih baik daripada penggunaan 
protokol SCTP tanpa menggunakan mekanisme ECN dan AVQ

2. SCTP dengan ECN dan AVQ mengungguli TCP namun belum dapat mengungguli UDP.

\section{SARAN}

Untuk pengembangan penelitian lebih lanjut, diberikan saran sebagai berikut:

1. Penelitian berikutnya dapat melakukan pengujian kualitas VoIP untuk jenis Active Queue Management (AQM) lain. Selain AVQ ada beberapa jenis AQM lain, misalnya ARED, PI, SFB, RRED dan REM.

2. Penelitian berikutnya dapat mengimplementasikan ECN pada SCTP dan melakukan pengujian pada sistem nyata. Pengujian pada sistem nyata dapat menutupi asumsi-asumsi yang dilakukan pada pengujian simulasi.

\section{DAFTAR PUSTAKA}

[1] Rakocevic,V., 2004, Congestion Control for Multimedia Applications in the Wireless Internet, International Journal of Communication Systems, 17,723-734.

[2] Lim, P.H., Myungchul, K. dan Jeong-Seon, K., 2007, Evaluation of Stream Control Transmission Protocol as a Transport for VoIP over WLAN, International Conference on Advanced Communications Technology 2007, Paris.

[3] Asodi, S., Ganesh, S.V., Seshadri, E. dan Singh, P.K., 2009, Evaluation of Transport layer Protocols for Voice Transmission in Various Network Scenarios, International Conference on the Applications of Digital Information and Web Technologies 2009, London, 4-6 Agustus 2009.

[4] Gangurde, P., Waware, S. dan Sarwade, N., 2012, Simulation of TCP, UDP and SCTP with Constant Traffic for VOIP Services, International Journal of Engineering Research and Applications (IJERA), ISSN: 2248-9622, 2, 1245-1248.

[5] Reguera, V.A., Paliza, F.Á., Fernandez, E.M.G. dan Godoy, W., 2008, On the Impact of Active Queue Management on VoIP Quality of Service, Computer Communications, 1, 31, 73-87, http://www.sciencedirect.com/science/article/pii/S0140366407004148.

[6] Ye, G., Saadawi, T.N. dan Lee, M., 2003, Using Explicit Congestion Notification in Stream Control Transmission Protocol in Lossy Networks, 23rd International Conference on Distributed Computing Systems Workshops, Macau, 19-22 Mei 2003.

[ 7 Tahir, H.M., Abas, M.S., Elhalabi, M. J.M., Puteh, N., Othman, A., Zain, N.M., Dahalin, Z.M., Ismail, M.H., Zaini, K.M. dan Hussin, M.Z., 2011, Improving Network Performance by Enabling Explicit Congestion Notification (ECN) in SCTP Control Chunks, Snasel, V., Platos, J., dan Eyas El-Qawasme, E., Digital Information Processing and Communications, 188, Springer, Heidelberg.

[8] Stewart, R., 2007, Stream Control Transmission Protocol, http://tools.ietf.org/html/rfc4960, diakses 03 Januari 2013. 
[9] Stewart, R., Tuexen, M. dan Dong, X., 2014, ECN for Stream Control Transmission Protocol (SCTP), http://tools.ietf.org/id/draft-stewart-tsvwg-sctpecn-00.txt, diakses 1 Januari 2014

[10] Kunniyur, S.S. dan Srikant, R., 2004, An Adaptive Virtual Queue (AVQ) Algorithm for Active Queue Management, The IEEE/ACM Transactions on Networking, 2, 21, 286-299

[11] ITU-T, 2009, ITU-T Recommendation G.107, The E-Model: A Computational model for Use in Transmission Planning. 